\title{
K-12 Participation Is Instrumental In Enhancing Undergraduate Research And Scholarship Experience
}

\author{
Changwoo Ahn, George Mason University, USA
}

\begin{abstract}
This article reports a case of incorporating a field-based ecological project as a resource into an undergraduate research and scholarship (RS) intensive course. Student research projects were conducted in an outdoor experimental compound with wetland mesocosms as well as in local created wetlands to study soil organic matter content as part of an on-going research project that focuses on the abilities of wetland in sequestering carbon. The course, designated as a RS intensive course by the university in both biology and environmental science, was also newly designed with a K-12 outreach component for training undergraduates in science education and communication. The public presentation component required all participating undergraduates to present and communicate their semester-long science project outcomes to and with K-12 students invited from local middle and high schools at the end of the semester. This activity challenged the students to review their study backgrounds, concepts, and results thoroughly to be able to explain them to and answer a variety of questions from K-12 students. The activity seemed to enhance research and scholarship experiences among the undergraduate students, being more effective than presenting to their own peers in a classroom setting. The students also learned all major steps in doing science, including exercises in literature review, building hypotheses, lab/fieldwork and data analysis. The experience obtained and approach taken in the study may be considered and adopted in reinforcing undergraduate RS experiences at other institutions and in other disciplines.
\end{abstract}

Keywords: Undergraduate Research and Scholarship; Ecological Sustainability; Wetland Mesocosm Compound; K-12 science education

\section{INTRODUCTION}

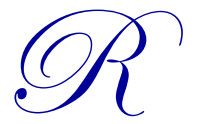

esearch and scholarship in undergraduate science education has recently been emphasized in many colleges and universities. However, there has been little information that is specific and organized enough to guide instructors on how to teach undergraduates the research process effectively. A great deal of research has been conducted on science teaching to improve science literacy among undergraduates, but there have not been numerous cases that clearly show what methodologies and procedures work to materialize the role of "research" on science teaching. Research and scholarship training is not just for those who plan to go to graduate school or seek their career in research and academia.

There is a lack of courses that teach ecological sustainability that mostly deals with issues relating to biodiversity and ecosystem services. Many ecology or environmental science majors will enter careers and occupations related to environmental consulting and other forms of ecological field research and activities. Ecology or environmental science is an interdisciplinary subject matter in real need of students being given the opportunity to participate actively in the process of research and scholarship. In this article I am reporting a case of a relatively a new course that I have recently taught, which is designed to teach undergraduates research methods and scholarship specific to biology and environmental science. 


\section{COURSE APPROACH}

The course was created with supports from George Mason University's (GMU) initiative called "Students as Scholars" that intends to enhance undergraduate teaching through research and scholarship (RS). In natural science courses - and especially in biology and environmental science-field-based, hands-on experience is almost a mandatory approach through which students learn skills and methods to be able to conduct a research project, but those activities are not necessarily common in undergraduate courses. Undergraduate students often take a number of classes, yet are not being given an opportunity to use and integrate the knowledge obtained in those courses in an organized way through a variety of research and scholarship activities in a course. My course entitled "Ecological Sustainability" was designed to address this need.

The course was designed to teach undergraduates the process and practice of research and scholarship with a timely and popular subject of interest. The theme in the course for the spring semester of 2013 was "wetland plant diversity and soil organic matter (SOM) accumulation." As an ecosystem ecologist, I decided to use the best of my experience and expertise from fields and labs in teaching research processes and methodology to undergraduates with one of my ongoing research projects. I have always tried to link research and teaching in my performance as a professor throughout my academic career. When I designed my RS course I was at an early stage of one of my research projects that focuses on studying the effects of planting diversity and time (i.e., age) on ecosystem functional development in wetlands created to mitigate the loss of natural wetlands (Korol \& Ahn, 2014; Means, Ahn, \& Korol, 2014). I transformed some aspects of the project into a resource for student class project materials. The course was built with several key activities that are pivotal to scholarly inquiries, including peer-reviewed journal article study (i.e., critical reading, summary, presentation, and discussion of the article), hypothesis forming exercise, field trips to local wetlands and wetland mesocosm compound, participating in soil samples and laboratory analysis of the collected samples, data analysis and group discussion of the results, writing a paper in a journal article format and style, and communicating the results of the study with the public.

Students were encouraged and directed to act as though they were an environmental or ecological researcher, and worked both individually and in groups of two or three students, depending on the type of activity. For example, students individually studied literature that is original and relevant in both scope and subject matter for the research project. Hypothesis formation exercise was conducted by group, so the students were challenged to build hypotheses for their research project after reviewing relevant literature and visiting wetland sites. Each group came up with a hypothesis after intensive group discussion and presented in front of the entire class to get feedback and answer questions from the other group members. Field data collection and lab processing of samples were a group task as well. They would come up with a plan to divide the sampling job among the group members, and often devised a sampling scheme, collected data and performed the analyses of those data to test their hypotheses together as a group. Writing a research paper was an individual task at the end of the semester.

Through this kind of scholarly inquiry and investigation approach that is common in natural sciences, students will learn first-hand what it means to produce scholarship in the field of biology and environmental science. The students' task was to assess soil organic matter as a surrogate of soil organic carbon (e.g., approximately organic carbon is half of the organic matter in wetland soils; Ahn \& Jones, 2013) in both local created wetlands of varying ages and mesocosm wetlands created with different planting diversity schemes (Korol \& Ahn, 2014). 


\title{
STEPS IN COURSE AND SPECIFICACTIVITIES
}

\author{
In the following sections I will discuss how I provide a scaffold for the development of research skills \\ through a series of steps and activities.
}

\section{Critical Reading of Peer-Reviewed Journal Articles}

The goal of the lecture portion of this course was to provide as much information as possible on each process involved in scientific research and specific knowledge on wetlands and plant diversity. I prepared weekly or biweekly reading materials, most of which were peer-reviewed journal articles on the topic, carefully prepared starting with a relatively easy one to read as a non-researcher/scientist in the field. Students were asked to prepare a summary (2-3 pages with 800-1000 words limit) of the paper they read, followed by two to three questions. Students searched literature or online sources (e.g., I taught how to use Web of Science for peer-reviewed journal articles with keywords) to look up to answer at least one of their own questions that they raised while summarizing the paper. I specifically chose nine journal articles and scholarly book chapters throughout the semester with specific key words such as created wetlands, plant diversity, and wetland soils. Students as a group took turns in presenting a paper summary through PowerPoint presentation each week, and tried to answer and discuss the questions raised by the other students, as well as their own. My involvement was heavy at the beginning of the semester with lectures on the content of the paper along with instructions on how to read graphs and tables correctly in science papers. In addition, I incorporated a special session that ran for 2 hours on simple statistics along with my lectures on how to read and interpret graphs and tables in science journal articles. Although the majority of the students had taken biostatistics courses previously, they rarely applied this prior knowledge to their own scientific inquiries. Thus, the statistics review session worked really well to pull together and refresh the pieces of knowledge they have gained from other classes and to challenge them to apply it to the research activities of this class. As time went by the students showed a visible progress in their reading, questioning, and discussing abilities on the given topic of a paper.

For the first half of the semester students learned scientific methodology, basics in wetland ecology and soil science, and any information and knowledge pertinent to being able to conduct their research projects with the topic chosen for the semester. In addition, I arranged a couple of guest lectures on the topic relevant to the research projects so that the students could meet and learn from working scientists in the field. The type of critical reading and discussion of scientific papers familiarized students with scientific literacy, units of measurement, and the correct way to read and interpret graphs and tables that are often confusing and may scare nonexperts.

\section{Exercising Hypotheses Testing}

Hypotheses are not guesses. They are only made after a student learns something about the system that they deal with. Students practice building their own research questions based on a broader scope of the research idea explained, from having read and studied journal articles and other complementary materials handed out on wetland plant diversity and soils. Each group presented their hypotheses or research questions after their internal group discussion and received questions and feedback from the other students. Then students went through another round of hypotheses forming practice and presented their final, revised hypotheses of their research project to the entire class, aligned with their plans of how to test their hypotheses and what may be involved in their methods and approaches for the testing.

\section{Wetland Mesocosm Compound: Outdoor Teaching and Research Facility}

I had a plan of building an outdoor teaching and research infrastructure for environmental biology/science education when I started my career as a professor at GMU in 2003. After several years of work "Ahn Wetland Mesocosm Compound" (Ahn, 2012) was built on the west campus of GMU within the Intramural Arena, on a 100year floodplain. Students from my classes and my research group contributed greatly over the years to the development of the compound. The compound currently has tap water and electricity, a tool shed, and a total of 60 wetland mesocosms (150 gallon each), and two 500-gallon stock tanks. Mesocosms have long been considered useful research tools for ecological studies of aquatic and terrestrial ecosystems. Use of mesocosms, particularly in 
biology and ecosystem science, has been common over the last two decades in studies of the fate and effect of pollutants, biogeochemical cycles and the effects of nutrients on ecosystem dynamics (Ahn \& Mitsch 2002). Mesocosms provide a means of conducting ecosystem-level experiments under replicated, controlled, and repeatable conditions at a relatively low cost (Ahn \& Mitsch, 2002). A set of 40 mesocosms were established in early 2013 and have been used for an externally-funded project on the effects of plant diversity on wetland ecosystem services as well as for the class activities described in this paper (see Figure 1).

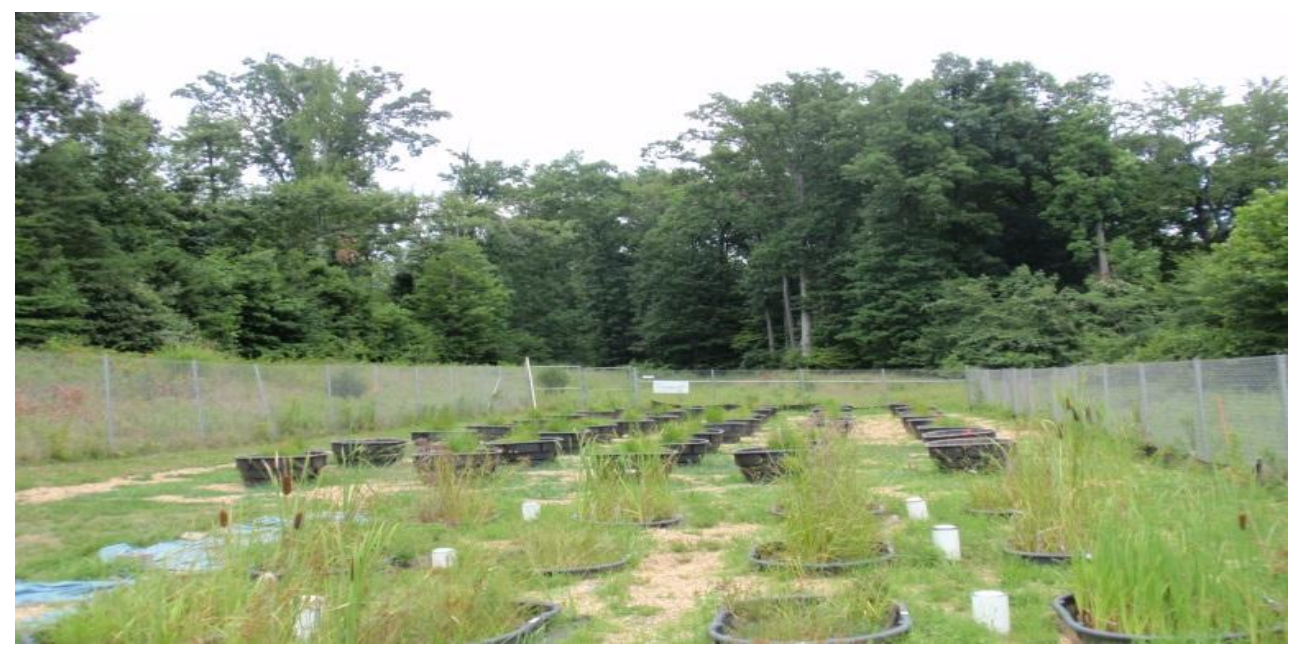

Figure 1. Wetland mesocosm compound used for the study

\section{Lab and Field Activities}

There was a lab and field component to the course, which was accounted for about 2.5 hours on Fridays, and involved field trips to local and mesocosm wetlands, field sample collection, and lab analysis of any samples collected (i.e., wetland soils). The goals of the lab and field portion of the class were as follow. First, I wanted my students to see created wetlands commonly found in the northern Virginia with a few of field sites my research team have studied for several years. Second, I wanted the students to gain hands-on experience and master basic skills and field techniques used in soil samplings, water regime characterization, and plant identification. Last, I wanted them to experience some part of lab analysis of the collected samples, including soil sample drying, weighing, and applying loss-on-ignition method (LOI: Ahn \& Jones, 2013) to quantify organic matter content in each soil sample. The field experience would provide the students with an idea of what fieldwork in ecology is like and a real sense of the data that may no longer seem to be "just numbers" afterwards. Students worked as a group for the lab and field portion throughout the semester.

There were always small lectures provided a week before or one class before a scheduled fieldwork to explain why and how we collect these samples and what information can be teased out from the analysis of those samples. Thus, students would understand the rationale of the experimental design and sampling protocol before conducting an actual field sampling. During the field training students verbally demonstrated their improved knowledge of the research subject in a way that cannot quite be conveyed in a classroom setting. Field-based learning in ecology and environmental science is a must and provides students with knowledge of an ecosystem that cannot be duplicated in a classroom setting: "the colors, sounds, smells, and textures experienced in a real wetland leave a lasting impression that makes the facts and figures all the more relevant" (Baldwin, 2001, p. 95). Figure 2 shows student activities in the lab and the fields. 


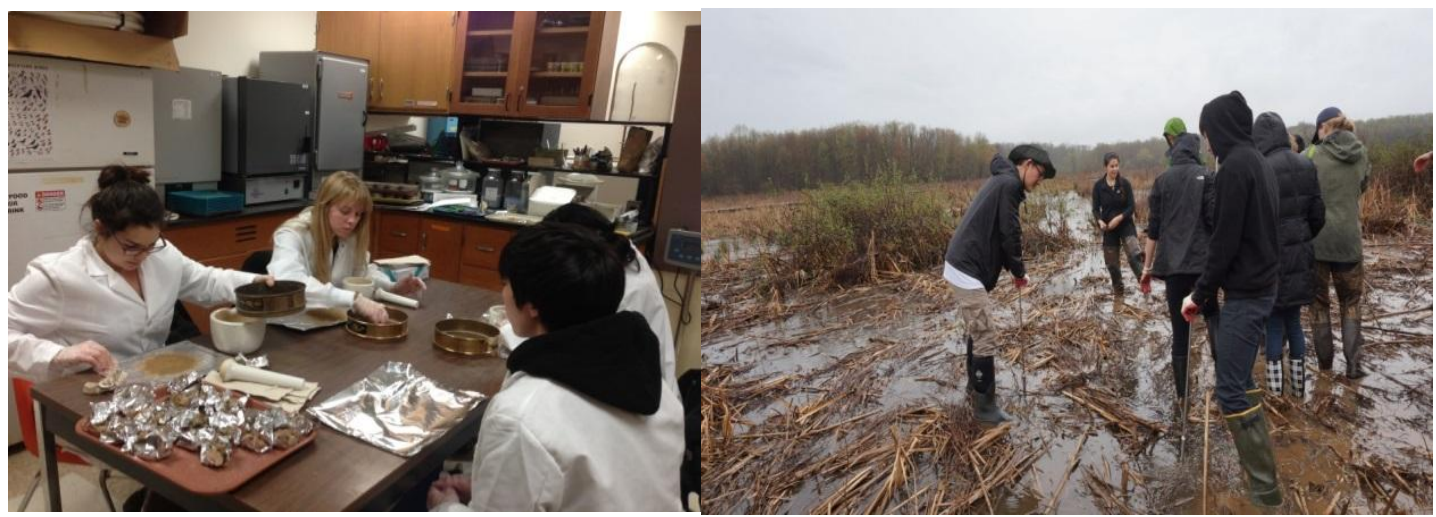

Figure 2. Student lab and field activities for wetland soil collection and processing for soil organic matter (SOM) analysis.

\section{Summary of Results}

The research questions had two parts. One was about the SOM as affected by planting diversity in wetland mesocosms, and the other was SOM comparison between three wetlands of varying ages created in the Virginia piedmont. The students collected the soil samples in both systems and followed a relatively simple lab procedure to analyze SOM (i.e., loss on ignition-LOI, see Ahn \& Jones, 2013 for details of methods) with my assistance. The students found no difference of SOM between created mesocosm wetlands with four different planting diversity, fairly due to a young age of the wetlands ( 1 yr; see Table 1), but found higher SOM content in the oldest created wetland compared to the other two younger wetlands in the fields (Table 1). I helped each student group with data analysis, using EXCEL and a common statistical software (MINITAB, 2006).

Table 1. Soil organic matter (SOM) content in wetland mesocosms as affected by planting diversity and SOM in wetlands of varying ages created in the Virginia piedmont studied for the course. Different alphabetic letters $(*)$ indicate significant differences between treatments within each column (Tukey's multiple pair-wise tests at $P<0.05$ ).

\begin{tabular}{|c|c|c|}
\hline Planting diversity in wetland mesocosms & & Mean SOM (\%) \\
\hline Monoculture & & $5.37 \mathrm{a}^{*}$ \\
\hline Two species mixture & & $5.53 \mathrm{a}$ \\
\hline Three species mixture & & $5.46 \mathrm{a}$ \\
\hline Four species mixture & & $5.54 \mathrm{a}$ \\
\hline Created wetland site & Age (yrs) & Mean SOM $(\%)$ \\
\hline Wetland A & 13 & $5.50 \mathrm{a}$ \\
\hline Wetland B & 11 & $4.29 b$ \\
\hline Wetland C & 6 & $3.70 \mathrm{~b}$ \\
\hline
\end{tabular}

\section{Writing a Research Paper and Creating a Poster}

All students were required to write a research paper theoretically being sent off to a journal. To facilitate the first, I designed one class session dedicated to a "writing workshop" where I instructed on how to write a manuscript for scientific journals, and also invited a guest speaker from the Students as Scholars program to do a lecture on how to make an effective poster for presentation. Those are all essential parts of scholarship training and experience. There was also a template for posters made available by the program.

\section{K-12 OUTREACH AS A KEY COMPONENT FOR UNDERGRADUATE RESEARCH AND SCHOLARSHIP}

The outcome of the research activities by undergraduates were presented in a few meetings on campus, including Students as Scholars undergraduate research forum, College of Science undergraduate research colloquium, and Innovative Teaching and Learning conference at GMU (Probst, 2013). Another major, new component I designed for this RS intensive course was a public presentation of students' research. Research and Scholarship training and experience may not come in a full circle without the presentation component. I often 
emphasize 4Ps (Propose, Present, Publish, and Participate) in my training and mentoring of graduate students and undergraduate research students for full-fledged research and scholarship activities, and encourage them to think about how one can combine activities for all 4Ps more effectively. Before the semester began while I was designing the course activities I arranged a meeting with science teachers from two local K-12 schools to invite them to Ahn Wetland Mesocosm Compound (Ahn, 2012) for our student presentation at the end of the semester (i.e., the first week of May for the spring semester of 2013). Involving K-12 students requires time and understanding of the schools' situations. Some schools I had contacted could not participate due to financial issues like the cost of running a school bus to take the students to the compound. The two local schools, one being a middle school and the other a high school, were greeted and welcomed by all undergraduate students in the class who prepared their posters and hung them on the fence of the compound (see Figure 3), getting ready for their public presentations. First each group gave the students and teachers visiting a short orientation about the wetland compound and what type of research they did, trying to put things in the context of ecological sustainability. After that, students were split into four groups to present each of their semester-long research project outcomes to the visitors. K-12 students were also split into small groups and assigned to each presenting group.

K-12 students showed a great curiosity with excitement of seeing small critters, including tadpoles, in the wetland mesocosms when they were given free time to look around before listening to each group's presentation. I was carefully watching each group's presentation and communication with the K-12 students. My intention for this type of activity was particularly geared to train science communication skills for undergraduate students. When the undergraduate students started their presentation, using the jargons and terms commonly used in ecological sciences for the experiment they conducted, the K-12 students stopped them and started asking questions, starting with very basic concepts about those. That inevitably and immediately challenged the undergraduate students to a great deal, in my observation, because they had to explain even a very basic concept like "What is a wetland?" in ecological and legal senses to help K-12 students understand the background and implications of the study. This kind of interaction continued throughout the presentation session that lasted 2 to 2.5 hours. Figure 3 shows the scenes of their presentation and communication sessions with the K-12 students at the wetland compound (see Laskowski, 2013).

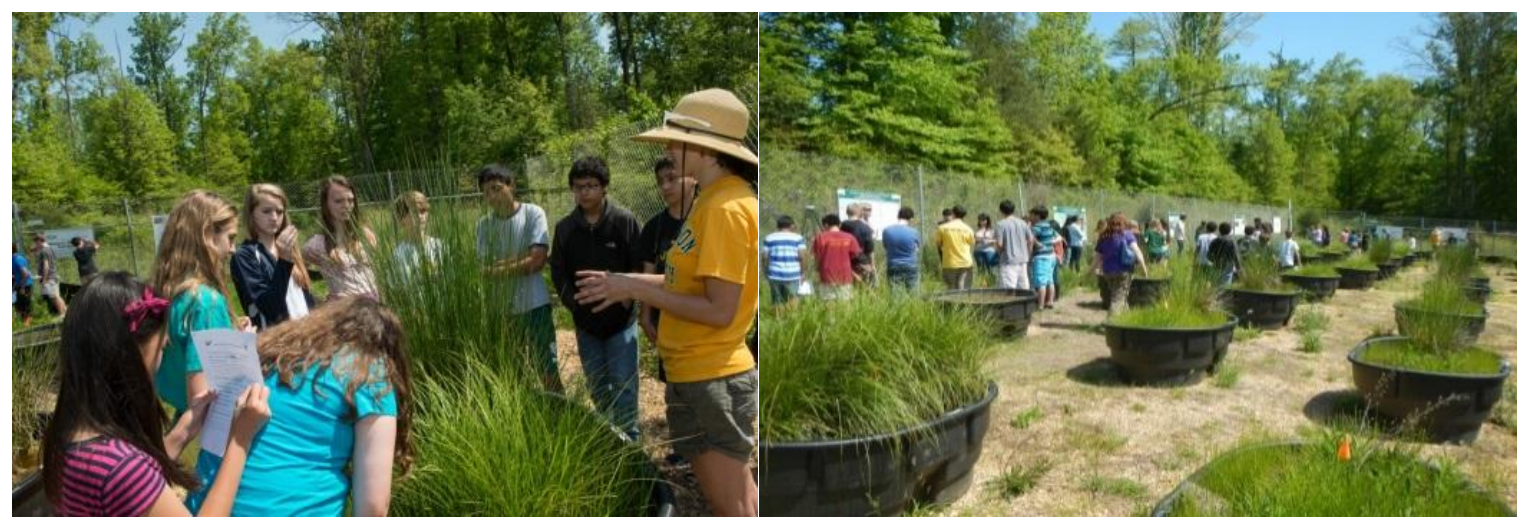

Figure 3. Undergraduate students presenting their research project at the end of semester to K-12 students invited as part of science communication exercise.

\section{After Public Presentation With K-12 Students}

I asked the undergraduates to respond to the following questions after their public presentation session:

1. Describe your experience of presenting your class project work to K-12 students.

2. Evaluate and/or comment on the above experience in terms of science communication.

The responses were extremely positive, especially when compared with their presentations to their own peers that they usually do in other classes. Also, many of them expressed that they felt confident and proud of their presentation and that they were gaining teaching experience from interacting with K-12 students. Many of them also 
mentioned that their interaction with K-12 students during their presentation was difficult, yet actually taught them a great deal about what it takes to communicate about science, which is an important aspect of research and scholarship. Speaking in scientific terms, then translating it to common terms for K-12 students, seemed to really help undergraduate students consolidate and reinforce the learning experiences they gained throughout the semester. Interacting with K-12 age groups may be a bit awkward for some of the undergraduates who never had previous experience engaging younger children in any type of science communication, but all of the students acknowledged that the exercise was very helpful and wonderful, and also seemed to get them to think about what it may take to communicate science with the general public and how critical public support can be in enhancing ecological sustainability.

\section{CONCLUSION AND RECOMMENDATIONS}

In this article I have presented and explained a case of an RS intensive course in biology and environmental science that I have recently taught. I found that K-12 participation in the presentation phase of the course was instrumental in enhancing research and scholarship experience in undergraduate science education. In the future I would like to continue to work with the university to develop a suite of measures to track and evaluate different approaches and methods that can be adopted to improve undergraduate research and scholarship experiences. One middle school science teacher came to the session for student presentations with a short questionnaire prepared for her students to fill out, which asked what the projects and outcomes were along with questions about hypotheses and variables of the projects. I had the opportunity to look at the middle school students' responses later and realized that if I could get to work with science teachers ahead of time on the questions and measures to be used to quantitatively evaluate the learning outcomes and impacts on both sides, it would be greatly beneficial for STEM education in both K-12 and undergraduates, which necessitates a further study and discussion. Regardless, the experience presented in this article may provide insights that can further enhance undergraduate research and scholarship experiences in the future in other disciplines and universities.

\section{ACKNOWLEDGMENTS}

Research and teaching activities described here were supported by many parties, including Thomas F. and Kate Miller Jeffress Memorial Trust, Wetland Studies and Solution, Inc., Sustainability Greenfund at GMU, and Students as Scholars program by OSCAR at GMU. Special thanks go to Suzanne Dee, Rita Peralta, Alicia Korol, Kevin Kim, Jonathan Castellano, and many other students for participating in the building of the Ahn Wetland Mesocosm Compound used for the study. I am grateful to students in Ecological Sustainability (EVPP378/BIO1379) classes in spring 2012 for assistance with and participation in the installation and planting of the experimental mesocosms used for the study. Thanks also go to students in Wetland Ecology and Management (EVPP 644) and Ecological Engineering and Ecosystem Restoration (EVPP 355) at George Mason University, and in General Biology (BIO 102) at Northern Virginia Community College who also participated in the establishment of Ahn Wetland Mesocosm Compound over the years.

\section{AUTHOR INFORMATION}

Dr. Ahn is an Associate Professor in Environmental Science and Policy, and an associated faculty member in Biology at GMU. Ahn is a wetland ecosystem ecologist and teaches Wetland Ecology and Management, Ecological Sustainability, Ecological Engineering and Ecosystem Restoration. Ecological Sustainability is a research and scholarship intensive course for undergraduates by Students as Scholars initiative. Ahn is dedicated to developing and innovating methods of teaching that will incorporate strong research experiences into undergraduate education. Ahn has been a mentor for Project SEED at the American Chemical Society and is also a book review editor for Ecological Engineering-the Journal of Ecosystem Restoration. 


\section{REFERENCES}

Ahn, C. (2012, Fall). Wetland mesocosm compound. GREENovation, Fairfax, VA: George Mason University, Department of Environmental Science and Policy.

Ahn, C. (2014). Transforming a research project into a resource in undergraduate science teaching-The case of a field-based learning in ecological sustainability, Abstract of Council on Undergraduate Research National Meeting, Washington, DC.

Ahn, C., \& Jones, S. (2013). Assessing organic matter and organic carbon contents of soils of created mitigation wetlands in Virginia. Environmental Engineering Research, 18(3), 151-156.

Ahn, C., \& Mitsch, W. J. (2002). Scaling considerations of mesocosm wetlands in simulating large created freshwater marshes. Ecological Engineering, 18, 327-342.

Baldwin, A. H. (2001). Got mud? Field-based learning in wetland ecology. Journal of College Science Teaching, 31(2), 94-100.

Korol, A., \& Ahn, C. (2014). Trade-offs between species functional performance and competitive ability determine the effects of wetland macrophyte diversity on net primary productivity. Abstract of Joint Aquatic Sciences Meeting, Bridging Genes to Ecosystems, Portland, OR.

Means, M., Ahn, C., \& Korol, A. (2014). Potential carbon storage by four herbaceous wetland species as affected by plant functional diversity. Abstract of Joint Aquatic Sciences Meeting, Bridging Genes to Ecosystems, Portland, OR.

Minitab. (2006). Statistical software. Ver. 15.0 for Windows XP. State College, PA: Author.

Laskowski, T. (2013, May 17). Student-to-student explore wetland research. George Mason University News. Retrieved from http://newsdesk.gmu.edu/2013/05/student-to-student-presentations-explore-wetlandsresearch/

Probst, K. (2013, September 17). Mason's Innovations in Teaching and Learning Conference fosters community building. George Mason University News. Retrieved from https://newsdesk.gmu.edu/2013/09/masonsinnovations-teaching-learning-conference-fosters-community-building/ 